\title{
Vancomycin extravasation: Evaluation, treatment, and avoidance of this adverse drug event
}

\author{
Vincent Peyko, Evan Sasson \\ Clinical Coordinator of Infectious Diseases Pharmacotherapy, Department pf Pharmacy, Kingsbrook Jewish Medical Center, \\ Brooklyn, NY, USA
}

Received: May 11, 2016

DOI: $10.5430 /$ crim.v3n3p40
Accepted: June 14, 2016

Online Published: June 16, 2016

\begin{abstract}
Purpose: To report the presentation, management, and potential future avoidance of vancomycin extravasation.

Summary: An 84-year-old woman was admitted to the emergency department due to observed seizures that progressed to status epilepticus. Status epilepticus was controlled, but the patient developed hospital-acquired pneumonia, requiring treatment with vancomycin and cefepime. During treatment with vancomycin, extravasation occurred during peripheral administration. Cold packs were immediately applied to the lesion for the next 24 hours with common gauze open dressings with frequent changes, and silver sulfadiazine $1 \%$ topical application once daily were started on the day after extravasation. While skin necrosis developed, it did not require surgical intervention and common gauze open dressings with frequent changes and silver sulfadiazine $1 \%$ topically were continued until the wound was healed.

Conclusion: Although the package insert warns of extravasation with potential necrosis during vancomycin administration, this case highlights a potentially under-reported adverse event. Vancomycin extravasation was successfully managed by utilizing cold compress for the first 24 hours post-extravasation with common gauze open dressings and silver sulfadiazine $1 \%$ until the wound was healed. With a potential for vancomycin extravasation when administered peripherally, we would recommend central venous administration.
\end{abstract}

Key Words: Vancomycin administration, Extravasation, Necrosis, Vesicant

\section{INTRODUCTION}

Vancomycin was approved by the FDA in $1958 .^{[1]}$ The original product was obtained by fermentation and was composed of up to $70 \%$ impurities. Initial trials reported little observed toxicity which was typically infusion related, including venous irritation, phlebitis, fever, chills, and rash. Other observed adverse effects included ototoxicity and nephrotoxicity. ${ }^{[2]}$ During this time period, vancomycin was considered a second-line anti-staphylococcal agent due to its nephrotoxic effects. ${ }^{[3]}$ Over time, use of more purified product eliminated much of the observed infusion-related chills and skin rash.
In addition, ototoxicty had become considered uncommon. ${ }^{[2]}$ By the 1970s, these newer vancomycin formulations without impurities were introduced and the nephrotoxic effects of the drug were diminished, but not eliminated.

Vancomycin is a glycopeptide antibiotic that inhibits cell wall synthesis and is used widely for gram-positive bacterial infections. ${ }^{[1]}$ Methicillin-resistant Staphylococcus aureus (MRSA) was first described in $1961 .^{[4]}$ Due to an inability to use penicillins or other beta-lactams to treat MRSA, an alternative agent was imperative, thus, vancomycin use began to increase ${ }^{[4]}$ Initially known as a hospital-acquired pathogen,

*Correspondence: Vincent Peyko, PharmD, BCPS; Email: VPeyko@kingsbrook.org; Address: 585 Schenectady Ave, Brooklyn, NY 11203, USA. 
appearance of MRSA in community isolates in the United States and throughout the world in the early 1980's saw a greater than 200-fold increase in vancomycin use over the next two decades. ${ }^{[2,5]}$

With increased use has come a better understanding of vancomycin toxicity and changes in the understanding of its side effects. A 2015 review article described the most common adverse effects of vancomycin. ${ }^{[6]}$ Red-man syndrome, hypersensitivity reactions, reversible neutropenia, thrombocytopenia and agranulocytosis, ototoxicty, and nephrotoxicity all continue to be reported in the literature. ${ }^{[6]}$ Redman syndrome is cited as the most common side effect, and nephrotoxicity remains controversial and on the forefront of current research. ${ }^{[7,8]}$ There are additional isolated reports of urticaria, exfoliative dermatitis, macular rashes, eosinophila, vasculitis, transient anaphylaxis, vascular collapse, IgA bullous dermatosis, exfoliative erythroderma, Stevens-Johnsons syndrome, and toxic epidermal necrolysis cited in the literature. ${ }^{[6,9]}$ While extravasation is described in the vancomycin package insert as an administration risk, a 2014 review article cites only three reported cases of vancomycin extravasation between 1961 and 2014, none of which discussed management. ${ }^{[10,11]}$ We would like to report a case of vancomycin extravasation, describing presentation, management and potential solutions to avert this adverse reaction in the future.

\section{CASE REPORT}

An 84-year-old African American woman was admitted to the emergency department due to observed seizures while at adult day care. The patient weighs $220 \mathrm{lbs}$ with a past medical history that includes anemia, asthma, atrial fibrillation, coronary artery disease, heart failure with preserved ejection fraction, hypertension, type 2 diabetes, and pneumonia. Surgical history includes a coronary artery bypass five years ago. Home medication list included: aspirin, docusate sodium, fluticasone/salmeterol, losartan, ferrous sulfate, furosemide, sitagliptin, metoprolol tartrate, insulin aspart, insulin glargine, prednisone, pantoprazole, and simvastatin. She had no documented history of any drug allergies.

The patient was still experiencing grand mal seizures at bedside following transfer to the emergency department, and was given two doses of intravenous lorazepam ( $2 \mathrm{mg}$ ). Seizures continued and the patient progressed to status epilepticus. Rocuronium (100 mg) and etomidate $(20 \mathrm{mg})$ were both administered to initiate rapid sequence intubation. Following successful intubation midazolam was started and a loading dose of levetiracetam (1,000 mg) was administered. Baseline labs taken following intubation revealed acute kidney injury, electrolyte abnormalities, and serum glucose above $700 \mathrm{mg} / \mathrm{dl}$. The hospital's diabetic ketoacidosis treatment protocol was initiated and the patient was transferred to the ICU for further treatment. Diabetic ketoacidosis resolved and seizures were subsequently controlled and the patient was continued on levetiracetam (500 mg twice daily).

Chest $\mathrm{x}$-ray on admission showed pulmonary congestion and cardiomegaly. Several follow up chest x-rays to ensure proper endotracheal tube placement showed no significant changes, but on hospital day 3 , a patchy opacification of the right lung base was noted. A diagnosis of hospital-acquired pneumonia was made and she was started on vancomycin (1,000 mg once daily) and cefepime (1,000 mg twice daily). The medications were administered through a 20-gauge peripherally inserted line (Hep-Lock) into the patient's right wrist. The first day of antibiotics were successfully administered without incident. On day two of treatment, the nurse noticed extravasation of vancomycin with severe painful blistering surrounding the infusion site on the patient's right wrist.

The resident physician was informed of the reaction and the vancomycin was discontinued. Cold packs were applied to the lesion. Common gauze open dressings with frequent changes and silver sulfadiazine $1 \%$ topical application once daily were started on the day after extravasation. Over the next week, necrotic tissue developed at the site of the reaction with ulcerated tissue under a black eschar. Local wound care was continued with wound dressings and silver sulfadiazine. Ten days after the extravasation, a bilateral venous duplex scan was ordered to assess potential clotting. The results of the procedure showed right thrombophlebitis at the mid-forearm near the cephalic vein. A surgery consult was ordered to determine if the patient would require wound debridement of the affected area, but it was deemed unnecessary. Pneumonia treatment was completed, seizures were controlled and the patient was discharged to a skilled nursing facility twelve days after extravasation. Common gauze open dressings and silver sulfadiazine were continued during stay at nursing facility. The wound improved over the next several weeks, with tissue granulation of the outer wound edges and underlying ulcer by 5 weeks post-extravasation.

\section{Discussion}

Vancomycin is acidic ( $\mathrm{pH}$ 2.5-4.0) and hyperosmolar (328 $\mathrm{mOsm} / \mathrm{L}$ ) which may make it a vesicant when administered through a peripheral line. ${ }^{[11]}$ This explains the package insert warning of inadvertent extravasation and potential necrosis and why a secure intravenous route of administration is recommended. ${ }^{[10]}$ Despite this warning, a 2014 review of the literature only cites three reports of vancomycin extravasation, with only one describing necrosis. ${ }^{[11]}$ The case by Bohm and Wong describes bullous dermatitis as a result of 
vancomycin extravasation. ${ }^{[12]}$ Paquette and colleagues simply identify quantitatively one occurrence of vancomycin extravasation in patients under 18 years of age from one facility, without any further details. ${ }^{[13]}$ Hoelen et al. is the only case we found in the literature to describe tissue necrosis as a result of vancomycin extravasation, yet without a description of management of the event. ${ }^{[14]}$

Thus, it is clear that information regarding skin necrosis as a result of vancomycin extravasation is scant, however, it is not unrecognized. Extravasation guidelines specifically cite vancomycin as a potential cause, recommending the use of cold compress in the event of extravasation. ${ }^{[15]} \mathrm{Had}-$ away and Chamallas review appropriate vancomycin administration and make clear that vancomycin will cause tissue damage if it escapes the vein to the subcutaneous tissue. ${ }^{[16]}$ While common admixtures of vancomycin are isotonic, the acidic $\mathrm{pH}$ warrants a need for infusion through a central venous catheter, despite distinct recommendations from the package insert. ${ }^{[16]}$ Peripherally inserted central catheters (PICC) are the preferred choice of central line in infectious diseases patients and due to the risk of phlebitis, thrombosis, and tissue sloughing if extravasation does occur and short catheters should be avoided. ${ }^{[16]}$ Our patient did not receive vancomycin through a central line. While the medication was administered via a secured intravenous route, according to the package insert, the recommendations by Hadaway and Chamallas, recommending central venous catheter administration of vancomycin, appear to be the more appropriate route and may warrant a change in the package insert. ${ }^{[10,16]}$

Extravasation in our patient followed a similar pattern as described by Al-Benna and colleagues, with initial pain, swelling, and skin discoloration. ${ }^{[17]}$ With no clear evidence-based vancomycin extravasation management in the literature, certain aspects of vesicant extravasation from chemotherapy guidelines and basic wound care were extrap- olated with this patient. ${ }^{[15,18]}$ We applied cold compresses to the extravasated area for the 24 hours. We also applied standard gauze open dressings with frequent changes and silver sulfadiazine $1 \%$ to the wound. While there is no clear evidence to suggest that silver products improve wound healing, they may decrease bacterial contamination on the wound surface and were used for such reasons in our patient. ${ }^{[19,20]}$ Over the next week, a black eschar overlying an ulcer developed. However, with surgery evaluating the patient and determining no need for any intervention, wound dressings and silver sulfadiazine $1 \%$ were continued with gradual healing occurring over the next 5 weeks, which eventually led to complete healing of the wound.

\section{Conclusion}

Vancomycin is a commonly used antibiotic whose utilization has increased due to higher MRSA prevalence. While a multitude of adverse effects are reported with vancomycin administration, there is very little written in the literature regarding vancomycin extravasation. Although the package insert warns of extravasation with potential necrosis, this is only the second case in the literature to report such adverse event. Furthermore, it is the first to report successful management of vancomycin extravasation utilizing cold compress for the first 24 hours post-extravasation with common gauze open dressings and silver sulfadiazine $1 \%$ topical application once daily until the wound is healed. With a clear potential for vancomycin extravasation when administered peripherally, we would recommend central venous administration, in accordance with nursing guidelines, and also would recommend an update to the package insert to reflect such a recommendation.

\section{CONFlicts OF InTEREST Disclosure}

The authors have declared no conflicts of interest.

\section{REFERENCES}

[1] Rubinstein E, Keynan Y. Vancomycin revisited-60 years later. Frontiers in Public Health. 2014; 2: 1-7. PMid:25401098 http://dx.d oi .org/10.3389/fpubh. 2014.00217

[2] Levine D. Vancomycin: A History. Clin Infect Dis. 2006; 42: S5-12 PMid:16323120 http://dx.doi.org/10.1086/491709

[3] Elyasi S, Khalili H, Dashti-Khavidaki S, et al. Vancomycin-induced nephrotoxicity: mechanism, incidence, risk factors and special populations. A literature review. Eur J Clin Pharmacol. 2012; 68: 1243-55. PMid:22411630 http://dx.doi.org/10.1007/s00228-012-1 259-9

[4] Hazelwood K, Brouse S, Pitcher W, et al. Vancomycin-associated nephrotoxicity: grave concern or death by character assassination? Am J Med. 2010; 123(2): 182.e1-182.e7. PMid:20103028 http://dx.doi.org/10.1016/j.amjmed.2009.05.031
[5] Kirst H, Thompson D, Nicas T. Historical yearly usage of vancomycin. Antimicrob Agents Chemother. 1998; 42: 1303-4 PMid:9593175

[6] Bruniera F, Ferreira F, Saviolli L, et al. The use of vancomycin with its therapeutic and adverse effects: a review. European Review of Medical and Pharmacological Sciences. 2015; 19: 694-700. PMid:25753888

[7] Cheung R, DiPiro J. Vancomycin: an update. Pharmacotherapy. 1986; 6: 153-69. PMid:3534799 http://dx.doi.org/10.1002/j.187 5-9114.1986.tb03471.x

[8] Alvarez R, Cortes L, Molina J, et al. Vancomycin: optimizing its clinical use. Antimicrob Agents Chemother. 2016 Feb 8. Pii: AAC.0314714 [Epub ahead of print].

[9] Rocha J, Kondo W, Baptista M, et al. Uncommon vancomycininduced side effects. The Brazilian Journal of Infectious Diseases. 
2002; 6: 196-200. PMid:12204187 http://dx.doi.org/10.15 90/S1413-86702002000400007

[10] Vancomycin $\mathrm{HCl}$ package insert. New York, NY: Pfizer Labs; 2010 Dec.

[11] Le A, Patel S. Extravasation of noncytotoxic drugs: a review of the literature. Ann Pharmacother. 2014; 48: 870-86. PMid:24714850 http://dx.doi.org/10.1177/1060028014527820

[12] Bohm N, Wong J. Bullous dermatosis associated with vancomycin extravasation. Am J Med Sci. 2012; 343: 177-79. PMid:22104428 http://dx.doi.org/10.1097/MAJ.0b013e318237bb47

[13] Paquette V, McGloin R, Northway T, et al. Describing intravenous extravasation in children (DIVE study). Can J Hosp Pharm. 2011; 64: 340-45. http://dx.doi.org/10.4212/cjhp.v64i5. 1069

[14] Hoelen D, Tjan D, van Vugt R, et al. Severe local vancomycin induced skin necrosis. Br J Clin Pharmacol. 2007; 64: 5534. PMid:17425624 http://dx.doi.org/10.1111/j.1365-212 $5.2007 .02897 . \mathrm{x}$
[15] Hurst S, McMillan M. Innovative solutions in critical care units: extravasation guidelines. Dimens Crit Care Nurs. 2004; 23: 125-8 PMid:15192356 http://dx.doi .org/10.1097/00003465-200 405000-00009

[16] Hadaway L, Chamallas S. Vancomycin: New Perspectives on an old drug. J Infus Nurs. 2003; 26: 278-84. PMid:14506360 http: //dx.doi.org/10.1097/00129804-200309000-00003

[17] Al-Benna S, O'Boyle C, Holley J. Extravasation injuries in adults. ISRN Dermatol. 2013; May 8; 2013: 856541.

[18] Schrijvers D. Extravasation: a dreaded complication of chemotherapy. Ann Oncol. 2003; 14(suppl): iii26-iii30. PMid:12821535 http://dx.doi.org/10.1093/annonc/mdg744

[19] Vermeulen H, van Hattem J, Storm-Versloot M, et al. Topical silver for treating infected wound. Cochrane Database Syst Rev. 2007; (1): CD005486. http://dx.doi.org/10.1002/14651858.cd 005486.pub2

[20] Woo K, Ayello E, Sibbald R. SILVER versus other antimicrobial dressings: best practices! Surg Technol Int. 2008; 17: 50. PMid:18802883 